\title{
"Ah, com certeza iam me dá alta, né...": autonomia no processo de cuidado em saúde de sujeitos hospitalizados
}

| ${ }^{1}$ Vívian de Andrade Hauck Pinto, ${ }^{2}$ Fernando Santana de Paiva I

Resumo: A autonomia é considerada um direito fundamental dos seres humanos e sua promoção e ampliação compóem diversas políticas públicas de saúde. Este estudo objetivou investigar os sentidos produzidos por sujeitos internados em um hospital universitário brasileiro em relação à sua autonomia no processo de cuidado na atenção terciária à saúde. Trata-se de pesquisa exploratória, de abordagem qualitativa. Foram entrevistadas seis pessoas em situação de internação entre julho e outubro de 2018. As entrevistas foram transcritas e analisadas segundo a análise de conteúdo do tipo temática. Os resultados foram divididos em duas categorias: 1) A experiência do adoecimento e da internação hospitalar; e 2) Relação entre a pessoa hospitalizada e a equipe de saúde. Considerase que ainda existem diversos desafios à coprodução de autonomia dos sujeitos internados, como a necessidade de se considerar as vicissitudes da experiência da internação e a fragilidade nos processos de comunicaçáo entre sujeitos e equipes de saúde. Alguns caminhos são apontados visando fortalecer a autonomia dos sujeitos hospitalizados, como um cuidado em saúde que acolha os sujeitos para além de sua doença e uma atuação profissional pautada em práticas de educação em saúde que fomentem o diálogo e considerem o saber dos sujeitos hospitalizados.

Palavras-chave: autonomia; hospitalização; cuidado em saúde.
${ }^{1}$ Psicologia, Universidade Federal de Juiz de Fora. Juiz de Fora-MG, Brasil (vivihauck@gmail.com). ORCID: 0000-0002-2730-7913

${ }^{2}$ Psicologia, Universidade Federal de Juiz de Fora. Juiz de Fora-MG, Brasil (fernandosantana.paiva@ yahoo.com.br). ORCID: 0000-0002-6030-9777

Recebido em: 05/08/2019 Aprovado em: 13/07/2020 Revisado em: 19/07/2021 


\section{Introdução}

As propostas de atenção à saúde da população no Brasil estão diretamente vinculadas ao Sistema Único de Saúde (SUS) brasileiro, que teve seus fundamentos delineados na $8^{a}$ Conferência Nacional de Saúde em 1986. Na mesma conferência, a saúde foi definida como um direito de todo cidadão brasileiro. Quatro anos depois, em 1990, aprovou-se a Lei Orgânica de Saúde (Lei no 8.080/90), que regula as açóes e serviços de saúde e especifica as atribuiçóes e a organização do SUS (PAIM et al., 2011). A partir da Lei Orgânica de Saúde, Machado et al. chamam atenção para os seguintes princípios do SUS:

[...] universalidade de acesso aos serviços de saúde em todos os níveis de assistência; inte-
gralidade de assistência, entendida como um conjunto articulado e contínuo das açóes e
serviços preventivos e curativos, individuais e coletivos, exigidos para cada caso em todos
os níveis de complexidade do sistema; divulgaçáo de informaçóes quanto ao potencial
dos serviços de saúde e sua utilização pelo usuário; igualdade da assistência à saúde, sem
preconceitos ou privilégios de qualquer espécie. (2017, p. 337).

Ferreira et al. (2014) salientam que, a partir da formalização do SUS, houve a necessidade de revisar e transformar o modelo de atenção à saúde até então vigente, o que levou ao aparecimento de novos enfoques como o da promoção de saúde, tido como uma maneira de pensar e de agir em saúde que leva em conta a autonomia dos cidadáos, capazes de instituir seu próprio modo de vida saudável a partir do conhecimento de seu direito político, econômico e social à saúde. Silva, Sá e Miranda (2013) apontam que temas como a integralidade da assistência, interdisciplinaridade e humanização têm recebido maior atenção nas discussões sobre saúde. Dentre as políticas públicas orientadas para o desenvolvimento destas temáticas, pode-se citar a Política Nacional de Humanizaçáo (PNH) de 2003, que propóe, dentre outras coisas, a produção de autonomia e protagonismo dos sujeitos implicados no processo saúde-doença e também a valorização da dimensão subjetiva e social nas práticas de atenção e gestão da saúde (BRASIL, 2010a).

O conceito de produção de autonomia que se encontra na Política Nacional de Humanização, por sua vez, não é exclusivo dessa política. A "preservação da autonomia das pessoas na defesa de sua integridade física e moral”, por exemplo, já compunha inicialmente a lei 8.080 como um princípio fundamental do SUS (BRASIL, 1990, p. 3). Além disso, a ampliação da autonomia dos sujeitos e coletividades é parte dos objetivos específicos da Política Nacional de Promoção à Saúde (BRASIL, 2010b). 
Segundo Fleury-Teixeira et al. (2008), a autonomia deve ser considerada norteadora para açôes de promoção de saúde, pois sua ampliação possibilita o aumento da capacidade orgânico-psíquica das pessoas, atuando como fator de proteção à saúde ao mesmo tempo em que sua restriçáo representa fator de risco para o desenvolvimento de doenças. A questão da autonomia dos usuários de saúde, portanto, mostra-se transversal a diversas temáticas importantes para a reflexão sobre as ações em saúde e inerente ao projeto de atenção à saúde proposto pelo SUS.

Ao considerar o conceito de autonomia - relacionado muitas vezes à liberdade e à capacidade de um sujeito agir intencionalmente (PEDROSA, 2016) - Soares e Camargo Jr. (2007) argumentam quanto à importância de não se confundir autonomia com individualismo, nem liberdade com algo descolado da realidade política e do contexto sociocultural no qual os indivíduos se inserem. Neste sentido, faz-se necessário reconhecer que a autonomia em uma sociedade democrática não é e não poderia ser absoluta, já que seu exercício se dá sempre em relação a outras pessoas e implica respeito ao outro, à sua subjetividade, saberes e valores (HAESER; BÜCHELE; BRZOZOWSKI, 2012; SOARES; CAMARGO JR.; 2007).

Partindo desta mesma noção, Campos e Campos (2009) propóem o entendimento da autonomia como a capacidade de um sujeito lidar com sua rede de dependências. A autonomia poderia ser considerada um processo de co-constituiçáo da capacidade de um sujeito de compreender a si mesmo e ao contexto e de agir com base nessa compreensão. A ideia de coprodução de autonomia deve-se à responsabilidade do sujeito diante de sua constituição bem como da realidade em que se insere, ao mesmo tempo em que depende de condiçóes externas, como as leis, a cultura, a economia, a existência de políticas públicas, o acesso à educação e à informação e à sua capacidade crítica, reflexiva e interpretativa diante das informaçóes recebidas/percebidas. Assim, um sujeito autônomo seria aquele que conhece algo, reflete e age interferindo em sua rede de dependências, sendo capaz, inclusive, de lidar com o sistema de poder no qual se insere. A autonomia pode ser considerada, portanto, uma categoria que sofrerá variaçóes a partir das posiçóes econômicas e sociais dos sujeitos, bem como de sua capacidade política de interferir sobre a sua vida e no mundo à sua volta (CAMPOS; CAMPOS, 2009; HAESER; BÜCHELE; BRZOZOWSKI, 2012).

Paula, Silva e Beraldi (2009) esclarecem que a autonomia na política de saúde brasileira constitui-se como um direito e que, portanto, é lícito que seja reivindicada. 
Levando em consideração a característica relativa e relacional da autonomia, as autoras apontam que, no processo saúde-doença, deve-se advogar pela intensificação de relaçôes e redes de autonomia/dependência necessárias ao cuidado da saúde, como a relação nos serviços de saúde e com a família, e não apenas defender a autodeterminação das pessoas. A intensificação dessas relaçôes seria ferramenta para o fortalecimento da autonomia, devendo-se precaver, entretanto, para que essas relações não se tornem uma sujeição daquele que está mais frágil aos que participam do cuidado de sua saúde, o que caracterizaria uma relação autoritária e paternalista.

Nesta direção, Campos e Campos (2009) apontam que uma das finalidades do trabalho em saúde seria a co-construção e ampliação do grau de autonomia das pessoas e, portanto, de sua capacidade de reflexão e ação. Assim, a práxis que se desenvolve no âmbito da saúde coletiva deveria apostar na implicaçáo dos sujeitos em seu processo de saúde, valorizando sua singularidade, bem como suas múltiplas relaçóes sociais. Entretanto, os autores supracitados reconhecem que a clínica tradicional desenvolvida pela medicina desde o século XIX não tem trabalhado no sentido de ampliação da autonomia dos sujeitos, considerando os pacientes como aqueles que não detêm conhecimento e que devem seguir prescriçôes.

Pensando na atenção terciária à saúde, Carneiro e Berti (2009) evidenciam que muitas vezes a pessoa hospitalizada não participa das decisóes sobre o curso de seu tratamento, tampouco são comunicadas sobre seu quadro clínico e sobre as opçóes de tratamento de maneira que consiga compreender as informaçóes. As decisões, assim, são tomadas unilateralmente pelo profissional de saúde, que assume uma posição de poder sobre o corpo do sujeito enfermo. A condição de enfermidade pode acarretar, por si, um sentimento de insegurança e de dependência na pessoa hospitalizada. Entretanto, tais sentimentos podem ser agravados quando estes sujeitos são incluídos em relaçóes assimétricas de poder. Em decorrência disso, a pessoa em situação de internação pode sentir-se constrangida a ponto de não se perceber no direito de questionar condutas, esclarecer dúvidas e opinar quanto a seu tratamento, aceitando passivamente todas as decisóes que lhe são impostas. Levando em consideraçáo seu direito à autonomia, as pessoas em situação de hospitalização seriam corresponsáveis pelo seu processo saúde-doença. No entanto, não há como se falar apenas em responsabilidade quando não existe estímulo para que sejam mais ativas, críticas e conscientes deste processo. 
Diante do exposto, pode-se pensar na importância do resgate e do reconhecimento da dimensão da autonomia para a prática em saúde (CAMPOS; CAMPOS, 2009), e de se conhecer os desafios para a consolidação de uma práxis que fortaleça a ampliação da autonomia dos usuários de saúde no Brasil. Assim, este trabalho parte de questionamentos acerca do exercício de autonomia no contexto de internação hospitalar e objetiva investigar os sentidos produzidos por sujeitos internados em um Hospital Universitário brasileiro quanto à sua autonomia no processo de cuidado.

\section{Metodologia}

Trata-se de pesquisa exploratória de abordagem qualitativa. $\mathrm{O}$ processo de trabalho da pesquisa foi dividido em fase exploratória, trabalho de campo e análise do material empírico (MINAYO, 2009). A pesquisa foi realizada em um Hospital Universitário do interior de Minas Gerais, no setor de internação da Clínica Médica, e empregou a observação participante e a entrevista semiestruturada como métodos no trabalho de campo.

Poderiam participar do estudo pessoas de ambos os sexos, maiores de 18 anos, que estivessem conscientes, orientadas auto e alopsiquicamente, capazes de estabelecer comunicação verbal e que estivessem internadas no referido hospital há pelo menos duas semanas. Foram entrevistados seis participantes, entre julho e outubro de 2018, havendo sido aplicado o critério de saturação para a definição do número de participantes. As entrevistas foram gravadas e transcritas, tendo sido analisadas a partir do método de análise de conteúdo temática (GOMES, 2009). Optamos por apresentar os relatos de maneira a preservar o vocabulário e expressóes regionais empregadas por nossos informantes, apresentados no quadro 1 , a seguir. ${ }^{1}$

Quadro 1. Descriçẫo das(os) entrevistadas(os)

\begin{tabular}{|c|c|c|c|c|c|c|}
\hline Nome & Sexo & Idade & Escolaridade & Situação laboral & $\begin{array}{c}\text { Motivo da } \\
\text { internação }\end{array}$ & $\begin{array}{c}\text { Tempo de } \\
\text { internação na } \\
\text { data da entrevista }\end{array}$ \\
\hline Conceição & $\mathrm{F}$ & 76 anos & $\begin{array}{c}\text { Ensino } \\
\text { fundamental } \\
\text { completo }\end{array}$ & Aposentada & $\begin{array}{c}\text { Muita dor nas } \\
\text { costas }\end{array}$ & 16 dias \\
\hline
\end{tabular}

continua... 


\begin{tabular}{|c|c|c|c|c|c|c|}
\hline Sônia & F & 44 anos & $\begin{array}{c}\text { Ensino } \\
\text { superior } \\
\text { incompleto }\end{array}$ & $\begin{array}{c}\text { Beneficiária } \\
\text { do Benefício } \\
\text { de Prestação } \\
\text { Continuada } \\
\text { (BPC), por } \\
\text { adoecimento }\end{array}$ & $\begin{array}{c}\text { Complicação em } \\
\text { quadro vascular }\end{array}$ & 38 dias \\
\hline Daniel & M & 23 anos & $\begin{array}{c}\text { Ensino médio } \\
\text { completo }\end{array}$ & $\begin{array}{c}\text { Era porteiro, } \\
\text { parou de } \\
\text { trabalhar após } \\
\text { adoecimento }\end{array}$ & $\begin{array}{c}\text { Infecção após } \\
\text { cirurgia de fêmur }\end{array}$ & 39 dias \\
\hline Adriana & F & 36 anos & $\begin{array}{c}\text { Ensino } \\
\text { fundamental } \\
\text { completo }\end{array}$ & $\begin{array}{c}\text { Beneficiária } \\
\text { do BPC, por } \\
\text { adoecimento }\end{array}$ & Abcesso & 37 dias \\
\hline Anderson & M & 29 anos & $\begin{array}{c}\text { Ensino } \\
\text { fundamental } \\
\text { incompleto }\end{array}$ & $\begin{array}{c}\text { Trabalha com } \\
\text { confecçáo de } \\
\text { roupas }\end{array}$ & Osteomielite & 14 dias \\
\hline Dalva & F & 65 anos & $\begin{array}{c}\text { Ensino } \\
\text { fundamental } \\
\text { incompleto }\end{array}$ & Aposentada & Descompensaçáo \\
glicêmica & 22 dias \\
\hline
\end{tabular}

Fonte: elaboração própria.

Houve submissão e aprovação do projeto de pesquisa pelo Comitê de Ética em Pesquisa em Seres Humanos do Hospital Universitário em questão e solicitação de assinatura pelos sujeitos participantes da pesquisa de um Termo de Consentimento Livre e Esclarecido, após explicação do objetivo da pesquisa, concedendo a gravação das entrevistas e garantindo aos mesmos o sigilo de sua identidade.

\section{Resultados e Discussão}

A partir das análises realizadas no material construído em diálogo com os sujeitos da pesquisa, foram construídas duas categorias, a saber: 1) Experiência de adoecimento e de internação hospitalar; 2) Relação entre a pessoa hospitalizada e a equipe de saúde.

\section{A experiência do adoecimento e da internaçáo hospitalar}

Foi possível identificar que a situação de adoecimento e, consequentemente, a experiência de internação hospitalar, vivenciadas pelos sujeitos da pesquisa, detêm 
representaçóes e sentidos que precisam ser considerados na (im)possiblidade de coprodução da autonomia no processo de cuidado em saúde.

A doença aparece como um fator limitante de atividades cotidianas, como o trabalho, e como causa de dores que necessitam ser suprimidas com o uso de medicamentos diversos, conforme relatado pelos entrevistados: "não quando (eu) tava podeno andá tava andando fazeno minhas minhas estrapulia ma agora eu num tô podendo, né” (Conceição), “aí trabalhava em firma lá agora não tô trabalhano porque n-num tá dando né porque eu tô doente, né” (Sônia), “antes do acidente era [...] trabalho casa viajava aí depois fiquei mais em casa por conta de num tinha como me locomovê né" (Daniel), "tomo muito dipirona paracetamol [...] e aí eu tomo analgésico (lá) amoxilina ( ) [...] ibuprofeno [...] aí eu tomo cada remédio pra num mantê as dores né (pra) num dá muita dor" (Anderson). Em contraponto, a saúde é percebida como algo importante que se tinha e que, agora, falta, como apontado por Conceição: “tá me faltando agora um pouco de saúde [...] muita, né?” (Conceição).

As falas acima remetem à caracterização feita por Canguilhem (2009) sobre a doença como um estado indesejável e socialmente desvalorizado, que pode gerar sentimentos de sofrimento e impotência no sujeito que experiencia o adoecimento. A doença, portanto, seria um estado contra o qual seria necessário lutar para poder continuar vivo e que teria como característica própria a interrupção do curso de algo. Ainda que o autor compreenda a doença também como uma norma da vida, podendo ser interpretada como uma possiblidade de reformulação e não só como privação, o mesmo admite que a doença seria uma norma qualitativamente inferior à da saúde, pois o ser vivo doente perde sua capacidade normativa, ou seja, de instituir novas normas em condições diferentes.

Canguilhem (2009) afirma também que aquilo que é patológico só o é após a avaliação do próprio indivíduo ao sofrer as consequências das transformaçôes advindas da doença, por exemplo, ao ver-se em uma nova situação e sentir-se incapaz de realizar as tarefas impostas pela mesma. Salienta, além disso, que a pessoa doente não é doente apenas para as outras pessoas, mas também em relação a si mesma e ao que era, o que confere certa nostalgia ao sujeito acerca de seu passado saudável.

Segundo Goidanich e Guzzo (2012), a doença suspende aquilo que estava previsto e leva a uma ruptura com o estilo de vida anterior do sujeito, colocando-o em uma situação de risco, uma mudança inesperada, temível e irreconhecível. Carretta (2011), por sua vez, chama atenção para as potencialidades humanas que 
ficam ameaçadas com o adoecimento, como a concepção de alternativas e a tomada de decisôes. Nunes et al. (2013) lembram ainda que o adoecimento coloca o sujeito em risco não só biológico, mas também de ordem psicossocial, podendo ficar vulnerável ao que os autores chamam de desequilíbrio emocional e ao surgimento de sintomas psicopatológicos.

A partir das entrevistas realizadas, tal fragilidade parece ser intensificada com a internação hospitalar, ainda que esta seja percebida também como uma oportunidade de melhora do quadro de adoecimento:

[...] o início foi muito difícil nossa no início eu chorava muito num aceitava assim sabe é mui - foi muito difícil sabe? agora pelo menos não agora pelo menos já aceitei sabe porque tem que melhorá né? Num adianta ficá doente adianta eu í pra casa ruim? (Sônia).

Ainda que percebido como necessário, o hospital também é experienciado como um lugar ruim, onde não se deseja estar, no qual os sujeitos se deparam com inúmeras privaçôes e com a ruptura da rotina e das relaçôes sociais já conhecidas. Para além disso, os efeitos do adoecimento e do tratamento parecem assumir um protagonismo no cotidiano dos sujeitos, como exemplificado nos trechos a seguir, quando os entrevistados foram questionados sobre a experiência de internação:

[...] é péssimo [...] é muito ruim mas a gente tem que passá né são os ossos do ofício [...] nu-num tem jeito num é bom [...] não é [...] (é) $\mathrm{m}$-m-minti (você) dizê assim ah é maravi - não é (acontece) você qué tá em casa ce (qué tá) com a sua família ce qué tá mais próximo de todo mundo [...] seus né [...] do que tá internada (dentro de) um hospital quem qué isso? (Sônia).

[...] ah uma experiência horrível [...] num desejaria isso nem pro meu pió inimigo e apesá de sê tratado bem essas coisa tudo ninguém merece ... passá por essas coisa não muito ruim [...] ficá longe de casa [...] privado de tudo [...] a gente acustuma com tudo nessa vida mas: num é bom não (Daniel).

[...] um ó [...] um ó ruim assim (pô) ficá internado num é (muito) bom não [...] em geral é bom entendeu um ó é sê ficá aqui memo na cama cê ficá preso na cama entendeu cê de - se ocê levantá (ali ce zonzo) ce fica zonzo [...] aí é efeito do remédio aí ce toma um otro remédio pra cort: o enjoo que dá e dá muito enjoo ce ficá por isso que eu falo que é o ó (Anderson)

Sobre a hospitalização, Pereira, Kruel e Dotto (2012) afirmam que há um impacto gerado na vida do sujeito hospitalizado quando este se vê em um lugar que possui um funcionamento alheio ao que está acostumado em sua vida, o que pode ocasionar a perda de sua identidade para uma outra produzida na instituição hospitalar. Instituição essa que, além de priorizar os procedimentos e rotinas necessárias para seu pleno funcionamento, possui uma gama de questôes administrativas e burocráticas 
que podem impor limites à capacidade decisória dos sujeitos. Os sujeitos, inseridos numa nova realidade e necessitando de cuidados, podem sentir-se impotentes frente a estas características do ambiente hospitalar e da fragilidade gerada pelo quadro de adoecimento, o que potencializaria sua dificuldade para a tomada autônoma de decisóes, por exemplo (BETTINELLI et al., 2011).

$\mathrm{Na}$ mesma direção, Carretta (2011) aponta que as padronizaçôes na assistência hospitalar, ainda que idealizem a recuperação da saúde dos sujeitos internados, buscam vincular o paciente à instituição de saúde em detrimento da personalização do cuidado. Neste sentido, a autora frisa que esta sistematização do cuidado e a normatizaçáo institucional do ambiente hospitalar proporcionam limitaçóes que podem favorecer a redução da autonomia do sujeito em situação de internação.

Questiona-se, portanto, qual é o cuidado oferecido na instituição hospitalar a estes sujeitos já tão fragilizados pela doença e, ainda mais, pela situação de internação em que se encontram. O cuidado em saúde no hospital se dá no encontro entre a pessoa internada e o profissional de saúde, de quem o sujeito internado depende fortemente, e é a qualidade deste encontro que poderá propiciar ou não o fortalecimento de autonomia dos sujeitos. Como nos lembra Carretta (2011), mesmo que em diferentes graus, as relaçôes de dependência estão presentes durante toda a vida e isto não é um impeditivo para que a autonomia esteja presente, em maior ou menor intensidade. Portanto, há aqui uma aposta de que o fortalecimento do cuidado em saúde pode levar a um aumento no grau de autonomia dos sujeitos hospitalizados.

Sobre o cuidado em saúde, Sá (2009, p. 656) nos lembra que cuidar consiste num processo de via dupla, que só pode se dar em relação com o outro, e que o trabalho em saúde deve ter como objeto não apenas as doenças, mas também "a vida, o prazer, a dor, o sofrimento, a morte em suas manifestaçôes singulares no corpo e na alma (no psiquismo) de cada sujeito". A autora indica ainda um caminho possível, em termos de gestão, para que a fraternidade, a solidariedade e o cuidado com o outro possam orientar as práticas de saúde:

Um desses caminhos se faz justamente trazendo o cuidado para o centro da gestáo em saúde, o que compreende duas perspectivas. Uma delas diz respeito à garantia do cuidado com a vida no modo de produzir o cuidado em saúde. Tal perspectiva significa, sobretudo, ter, como preocupação central, a garantia das condiçóes materiais, tecnológicas, humanas e organizacionais necessárias à escuta e ao acolhimento das demandas por cuidado que os sujeitos trazem aos serviços de saúde, bem como à eliminação ou (quando isto não for tecnicamente possível) à redução ao mínimo de seus sofrimentos." (SÁ, 2009, p. 660). 


\section{Relação entre a pessoa hospitalizada e a equipe de saúde}

Considerando a importância de um cuidado em saúde que se comprometa com a co-construção de autonomia dos sujeitos em situação de internação e que este cuidado está intimamente ligado à maneira como se relacionam os profissionais e os usuários dos serviços de saúde, buscamos elucidar, a partir desta segunda categoria construída, de que maneira têm se dado na prática cotidiana do serviço de saúde a relação entre a equipe e os sujeitos entrevistados. Neste sentido, um dos pontos abordados nas entrevistas dizia respeito à informação e compreensão dos sujeitos em situação de internação quanto a seu quadro clínico e a seu processo de hospitalização. Embora alguns dos sujeitos tenham afirmado que se sentem informados e confortáveis para tirar dúvidas com a equipe de saúde, outras falas sugerem que ainda existe uma barreira entre o que é dito pelo profissional de saúde e o que é compreendido pelos sujeitos, como pode ser percebido neste relato - "[a equipe de saúde] explica mas acaba que a gente num entende muito tamém não né explica do jeito deles lá” (Daniel) - e nos seguintes:

[...] tem coisa que eu num entendo que eu pergunto $q-$ ma-mas que que faz isso que que acontece com isso a gente tem que perguntá né porque tem coisas que realmente a gente num - meio té-técnico deles (e num) vai entendê [...] mas eu pergunto por que o que que acontece (Sônia).

[...] ela [a médica] passô aí (já veio né) ela fala comigo ma num guardo na minha cabeça não (menina) que que deu que que dexô de dá [...] eu num guardo na minha cabeça não aí eu - ela pega e fala com os minino (Dalva).

Um fator necessário para a coprodução de maiores graus de autonomia é, de acordo com Campos e Campos (2009), o acesso dos sujeitos à informação e, para além disso, sua capacidade de interpretar esta informação e utilizá-la de maneira crítica. Como podemos perceber pelas falas acima, parece haver um movimento da equipe de saúde para informar os sujeitos sobre seu quadro clínico, entretanto esta tentativa de transmissáo esbarra no uso de linguagem técnica, o que dificulta a compreensão dos sujeitos.

Tal cenário nos remete às discussões acerca da educação em saúde. De acordo com Ferreira et al. (2014), a educação em saúde seria inerente a todas as práticas desenvolvidas no âmbito do SUS e uma importante ferramenta para o processo de conscientização acerca de responsabilidade e direitos à saúde. Assim, lembramnos que educar é mais do que apenas informar, educar implica em possibilitar 
momentos de reflexão e ação que oportunizem às pessoas um aprendizado consciente, sem que haja intenção de controlar a vida do educando. No âmbito da saúde, a educação em saúde deveria buscar integrar saberes científicos e do senso comum, incorporando os saberes dos usuários dos serviços de saúde, de modo a fomentar diálogo, troca de experiências e um pensar crítico e reflexivo no encontro face a face entre estes últimos e os profissionais de saúde. Vale lembrar que as práticas educativas na atenção terciária podem estar presentes nos mais diversos momentos da assistência, desde a admissão no hospital até a realização de exames e procedimentos rotineiros.

A caracterização acima conferida às práticas de educação em saúde aproximase da concepção de educação popular em saúde, influenciada pelo Movimento de Educação Popular protagonizado por Paulo Freire na década de 1960. A educação popular em saúde baseia-se em processos educativos mais democráticos, que visam à emancipação dos sujeitos a partir do diálogo com os saberes prévios dos usuários dos serviços de saúde e da análise crítica da realidade (FALKENBERG et al., 2014). Na contramão dessa proposta, as falas dos entrevistados nos remetem a uma educação em saúde baseada na chamada educação sanitária, tipo de educação que almejaria apenas a transmissão de conhecimentos para prevenção de doenças, sem o interesse de problematizar ou contextualizar as informaçôes (FERREIRA et al., 2014). O que pode acontecer nesses casos é uma não compreensão do significado das informaçóes transmitidas, o que restringe a participação dos usuários dos serviços de saúde no processo de construção do cuidado à sua saúde.

Ainda considerando os processos de educação no campo da saúde, é importante nos atentarmos também para algumas especificidades da atenção terciária à saúde que podem contribuir para a fragilidade dos processos de comunicação. Como apontam Silva, Sá e Miranda (2013), o cuidado em saúde no hospital demanda um grau de sistematização de certas rotinas que influenciará nas relações possíveis entre a equipe de saúde e o sujeito internado. Dependendo da rigidez dessa rotina, pode-se culminar na diminuição do tempo que a equipe investe na escuta e interação com os sujeitos internados, como fica evidente no seguinte relato:

[...] então a gente (pergunta) pro pessoal da [especialidade médica] [...] que eles passam muita gente aí caba que [...] quando pergunta eles resume [...] caba explicano a gente num entende porque eles qué saí o mais rápido possível num [...] num tem jeito de entendê direito. (Daniel). 
Pensando em ferramentas que os serviços de atenção terciária à saúde podem utilizar na tentativa de garantir, ainda que minimamente, o respeito à autonomia dos usuários de saúde temos o Termo de Consentimento Informado e, no hospital pesquisado, o Termo de Responsabilidade assinado no processo de admissão no hospital. O primeiro é um documento que visa garantir o compartilhamento de informações entre o usuário e os profissionais de saúde e a tomada de decisão por parte do usuário de saúde quanto aos rumos de seu tratamento, no que tange a realização de procedimentos e exames, por exemplo. Já o segundo, no hospital estudado, é um termo que confere plena autorização aos médicos da instituição a promoverem o tratamento clínico e cirúrgico da enfermidade do usuário de saúde. Além disso, neste segundo termo, a pessoa que interna se compromete a respeitar as normas contidas no regulamento da instituição. Para que sejam de fato efetivos, é necessário que os profissionais de saúde informem ao paciente sobre o conteúdo dos documentos de maneira adequada - com linguagem acessível, que verifiquem a compreensão do usuário do serviço de saúde e que estimulem sua tomada de decisão, assegurando-se da voluntariedade de sua decisão a partir de um diálogo respeitoso e de cooperação mútua (SCARPELLI; FERREIRA; ZARZAR, 2007; PEDROSA, 2016).

Os participantes entrevistados foram questionados acerca dos documentos que assinaram ao adentrarem no hospital, dentre os quais, no hospital pesquisado, está incluído o Termo de Responsabilidade. As perguntas buscavam investigar se os entrevistados sabiam quais eram esses documentos e o conteúdo dos mesmos. Os relatos deram-se da seguinte maneira: "não quem assinô foi até minha filha" (Conceição), "não não aí se - assinei [...] (num lembro num - sabe que num lembro) [...] [...] mas acho que (eu devo) tê assinado sim... [...] aí - mas - num acho - tudo tranquilo num (tem) nada” (Sônia), "ah num lembro não [...] (já) tem bastante tempo" (Daniel), "então não sei não fui eu que assinei [...] foi a pessoa que tava comigo [...] porque [...] ela tava me acompanhano [...] aí o rapaz chamô ela ela foi lá dentro conversô com ele depois ela falô que tinha assinado alguns papeis" (Adriana), "num fui eu que me internei não foi meu minino" (Dalva), "ah só um termo de responsabilidade né [...] do hospital só que que eu assinei acho que foi só esse” (Anderson).

É importante observarmos que dentre os seis entrevistados, tanto Conceição quanto Adriana e Dalva não assinaram seus próprios documentos e o motivo de não os terem assinado não é claro para as entrevistadas. Inclusive, quando questionada sobre sua capacidade para assinar o documento no momento da admissão, Adriana chega a 
dizer que "com certeza" conseguiria assiná-lo. Além disso, todas as três entrevistadas citaram em outros momentos das entrevistas que chegaram a assinar termos de consentimento para exames e/ou procedimentos durante a internação, portanto questiona-se aqui o porquê de não terem elas próprias assinado, no momento de sua admissão no hospital, seus respectivos Termos de Responsabilidade, documento que confere tanto poder à equipe de saúde e à instituiçẫo e que se relaciona diretamente com seu tratamento de saúde. Outro ponto importante é que Anderson, apesar de se lembrar do nome do termo assinado, quando perguntado sobre o conteúdo do termo e se houve qualquer tipo de explicação sobre o conteúdo deste por parte da equipe de saúde, afirma: "não só falô que era termo do hospital" (Anderson).

$\mathrm{Na}$ mesma direção dos conteúdos encontrados aqui, alguns dados apontam que o Termo de Consentimento também não tem sido aplicado de modo a promover e fortalecer a autonomia dos sujeitos. Em pesquisa realizada no Hospital Escola Padre Albino, na cidade de Catanduva/SP, Sene et al. (2011) buscaram compreender a relação médico-paciente e seus aspectos éticos a partir da percepçáo de pacientes submetidos a um procedimento cirúrgico de urgência relativa. Como resultados, destaca-se que dos 43 participantes da pesquisa, 83,7\% afirmaram não terem sido informados sobre os riscos cirúrgicos antes do procedimento e $72,1 \%$ disseram não ter ciência de ter assinado um termo de consentimento, embora tal assinatura seja norma do hospital. Falas como "Me mandaram assinar um papel, mas não me explicaram nada" demonstram a não compreensão dos pacientes quanto ao que assinaram e um desrespeito por parte dos profissionais, bem como da própria instituição hospitalar, ao princípio da autonomia do usuário de saúde, já que a falta de informação excluiria qualquer possibilidade de reflexão e escolha.

Reconhecemos que a utilização ou não dos termos de responsabilidade não exime a obrigatoriedade das equipes de saúde em assegurar o máximo de informação aos sujeitos em processo de hospitalização. Trata-se, em nosso entender, de um direito que deve ser garantido a todas e todos visando promover sua efetiva autonomia no processo de cuidado em saúde. Na realidade pesquisada, a maneira como os sujeitos relatam o uso do Termo de Responsabilidade em seu processo de internaçáo serviu como mais um elemento para nos auxiliar no processo de compreensão do grau de autonomia experimentado pelos sujeitos.

A importância conferida aqui à informação dialogada a respeito do quadro de saúde dos sujeitos internados deve-se ao fato de esta estar intimamente ligada à 
possibilidade de tomada de decisão desses sujeitos. Possibilidade essa que aparece nas falas de dois dos entrevistados, Anderson e Adriana, quando questionados acerca de sua capacidade de tomar uma decisão durante seu tratamento: "então eu tento me informá o máximo por causa disso [...] ah eu tomo [decisão acerca do tratamento]" (Anderson); "ah acho que sim acho que sei bastante [...] porque [...] foi muito explicado [...] eu acho que eu teria sim né como opiná" (Adriana).

Em outra direçâo, as decisôes podem ser tomadas unilateralmente pelos profissionais de saúde, como aponta Daniel ao falar sobre uma cirurgia à qual foi submetido: "[...] eu num sei porque teve esse problema [...] desse começo de infecção lá [...] aí eles tinha que tê passado mais o meno a opção explicado o porquê [...] não deu opção não explicô qual ia fazê e fez" (Daniel). Segundo Bettinelli et al. (2011), é comum observarmos em nível hospitalar o fomento de uma atitude por parte da equipe que facilite o aumento no grau dependência do paciente que necessita ser cuidado.

Nesse sentido, no hospital, ações e decisões que poderiam se dar em conjunto com o paciente, ocorrem para o paciente. Em seu estudo acerca da experiência de idosos hospitalizados, Carretta (2011) encontrou falas que também sugerem a presença de tomada de decisóes unilaterais pelos profissionais de saúde. A autora menciona, então, o chamado paternalismo profissional gerado no ambiente hospitalar, estabelecido a partir de uma relação assimétrica de poder entre o profissional de saúde e o usuário do serviço e fortalecido pelas lacunas de comunicação. O paternalismo profissional, portanto, acaba por possibilitar a tomada de decisóes por parte dos profissionais de saúde em nome dos sujeitos hospitalizados. Essa tomada de decisão, ainda que não seja um direito concedido ao profissional, é executada rotineiramente.

Vale ressaltar que a tomada de decisão pelo profissional de saúde é um poder intimamente relacionado ao conhecimento técnico e científico que possuem. A valorização excessiva dos aspectos técnicos na instituição hospitalar pode ser um fator promotor de atitudes paternalistas, já que a importância conferida ao saber científico dos profissionais de saúde pode gerar um sentimento de desvalorização por parte da pessoa que é cuidada com relação a seu próprio saber (CARRETTA, 2011). Este sentimento por parte dos sujeitos em situação de internação pode ser percebido nas falas a seguir, quando as entrevistadas foram questionadas sobre a possibilidade de tomarem decisôes acerca de seu tratamento durante a internação: "[...] acho assim é cabe a eles né [...] eu n-n-não entendo muito (d-de) medicamento essas coisa assim [...] 
num é da minha [...] [...] mais eles mesmo" (Sônia), "acho que ela sabe qual que é o melhor né porque [...] se eu vim pra cá foi pra tratá [...] né fazê os exame tratá [...] mai eu prefiro nem sabê não [...] (ela) vai sabe” (Dalva) e ainda na fala a seguir:

[...] às vezes ce qué uma coisa o médico fala que tem que sê (aquilo e não aquilo tendeu) aí a gente quase ranca os cabelo fora ma num consegue năo [...] mas ele sabe melhó que nois a gente pega acaba dexano pra lá e pronto (Conceição).

Sobre o saber das pessoas hospitalizadas, Pereira, Kruel e Dotto (2012) afirmam que este é um saber que precisa ser levado em consideração. Ainda que o profissional de saúde possa conhecer muito bem as tecnologias, as técnicas e até o corpo da pessoa hospitalizada, quem "faz o uso" desse corpo adoecido ou ferido é a própria pessoa internada e não há como o profissional de saúde sozinho definir o melhor uso para este corpo e nem a maneira como essa pessoa irá se cuidar uma vez fora do hospital, por exemplo. Por isso é tão importante que se reconheça e se fortaleça a possibilidade de autonomia da pessoa hospitalizada. Quando há falta de informação sobre seu processo de saúde, relação assimétrica e de forte dependência entre os profissionais de saúde e as pessoas hospitalizadas e diferenciação no valor concedido ao saber científico e ao do próprio sujeito, há também o consequente fortalecimento de relaçóes paternalistas que enfraquecem a co-construção de autonomia dos sujeitos (CARRETTA, 2011).

Uma última questão construída a partir das entrevistas e que pode ser importante para compreendermos as relaçóes estabelecidas no ambiente hospitalar advém de uma pergunta sobre o que imaginavam que poderia acontecer caso se recusassem a realizar algum procedimento ou exame proposto pela equipe de saúde. Duas das entrevistadas afirmaram que isso não era uma possibilidade ou que isso nunca tinha "passado pela cabeça" delas e uma outra, que estaria se prejudicando se fizesse isso, pois a equipe de saúde não faria nada para causar mal a ela. Já Anderson aponta para seguinte possibilidade caso viesse a recusar algum procedimento ou exame: "ah com certeza iam me dá alta né" (Anderson), mesma possibilidade apontada por Conceição no relato a seguir:

[...] ah eu num faria quanto muito eles me daria alta [...] eles iam tentá ué de qualqué jeito né [...] e eu ia tentá de qualqué jeito não fazê [...] vão vê quem ia ganhá né? mas aí eu acho que no fim me dariam alta (Conceição).

A possibilidade identificada por estas duas pessoas com relação à alta em caso de qualquer recusa dentro do hospital nos leva a alguns apontamentos. Há que se 
considerar, primeiramente, que um hospital está sempre inserido num contexto socioeconômico e cultural e que o hospital pesquisado encontra-se inserido no contexto de saúde pública brasileira. De maneira geral, tal inserção caracteriza serviços de saúde com um grande volume de demanda por atendimentos e número insuficiente de recursos para atender tamanha demanda, o que gera longas listas de espera e dificuldade de acesso aos serviços. Neste sentido, é importante pensarmos, por exemplo, qual seria o grau de autonomia possível para pessoas que sentem que serão excluídas do serviço de saúde caso façam escolhas contrárias àquelas percebidas como corretas pela equipe deste serviço. Ou ainda, nesta mesma direção, que tipo de questionamentos e posicionamentos críticos poderíamos esperar de sujeitos que sentem sua, talvez única, chance de tratamento ser ameaçada em caso de discordância com as propostas oferecidas pela instituição hospitalar.

\section{Considerações finais}

Mais do que responder a perguntas, este trabalho buscou suscitar questionamentos e reflexôes acerca das possibilidades de produção de autonomia dos sujeitos em situação de internação hospitalar. Ainda que a produção de autonomia componha leis e políticas como um direito dos usuários dos serviços de saúde, o que vemos na prática do serviço investigado são inúmeros obstáculos e desafios a uma coconstrução de autonomia que conte com a participação dos profissionais de saúde e dos sujeitos internados.

A fragilidade intrínseca às situações de adoecimento e de internação hospitalar insere os sujeitos muitas vezes em relaçôes mais intensas de dependência. Além disso, a sistematização do funcionamento hospitalar, a valorização do saber técnico científico em detrimento do saber do sujeito hospitalizado e o paternalismo praticado por alguns profissionais podem enfraquecer processos de comunicação e participação do sujeito no seu processo de saúde e, consequentemente, a produção de sua autonomia. Alguns caminhos são apontados, como um cuidado em saúde que se proponha a escutar e acolher os sujeitos em suas demandas para além de sua doença e uma atuação profissional pautada em práticas de educação em saúde que se aproximem da concepção proposta pela educaçáo popular em saúde, ou seja, práticas que almejem fomentar o diálogo, a troca de experiências e um pensar crítico e reflexivo acerca dos processos de saúde, favorecendo o fortalecimento de práticas cada vez mais horizontalizadas e que levem em consideração o saber dos sujeitos em situação de internação. 
Cabe aqui ressaltar algumas possíveis limitaçôes do estudo. Com relação ao local da entrevista, cinco dos seis participantes optaram por permanecer no leito. Os quartos deste setor do hospital possuem uma média de três leitos cada, sendo assim, estes participantes concederam a entrevista na presença de outras pessoas, o que conferiu menor grau de privacidade para a realização das entrevistas. Ademais, fatores próprios do contexto de internação hospitalar, como interrupçôes nas entrevistas para a realização de procedimentos pela equipe de saúde, também podem ter interferido nos conteúdos apresentados.

Por fim, há que se ressaltar que a pesquisa não pretende esgotar as investigaçôes acerca desta temática, mas sim contribuir para que novos estudos possam ser realizados em vista de potencializarem uma práxis em saúde voltada para a coconstrução de autonomia dos usuários dos serviços de saúde e, especialmente, dos sujeitos em situação de adoecimento e internação hospitalar. ${ }^{2}$

\section{Referências}

BETTINELLI, L. A. et al. Autonomia e dependência: experiências de idosos na hospitalização. Revista Contexto \& Saúde, Ijuí, v. 10, n. 20, p. 727-732, jan-jun. 2011.

BRASIL. Lei Orgânica da Saúde. Lei no 8.080/90, de 19 de setembro de 1990. Dispóe sobre as condições para a promoção, proteção e recuperação da saúde, a organização e o funcionamento dos serviços correspondentes e dá outras providências. Diário Oficial da União, Brasília, DF, set. 1990. . Ministério da Saúde. HumanizaSUS: documento base para gestores e trabalhadores do SUS. Brasília, 2010a.

Ministério da Saúde. Política nacional de promoção da saúde. Brasília, $2010 \mathrm{~b}$.

CAMPOS, R. T. O.; CAMPOS, G. W. de S. Co-construção de autonomia: o sujeito em questão. In: CAMPOS, G. W. de S. et al. (Org.). Tratado de saúde coletiva. São Paulo: Hucitec, 2009. p. 669-87.

CANGUILHEM, G. O normal e o patológico. Rio de Janeiro: Forense Universitária, 2009, 154 p.

CARNEIRO, M. T. R.; BERTI, H. W. A autonomia de pessoas hospitalizadas em situação précirúrgica. Revista Mineira de Enfermagem, Belo Horizonte, v. 13, n. 1, p. 84-92, jan-mar. 2009.

CARRETTA, M. B. Experiência de idosos hospitalizados: a compreensão do fenômeno da autonomia. 2011. Dissertação (Mestrado em Envelhecimento Humano) - Universidade de Passo Fundo, Passo Fundo, 2011.

FALKENBERG, M. B. et al. Educação em saúde e educação na saúde: conceitos e implicaçóes para a saúde coletiva. Ciência \& Saúde Coletiva, Rio de Janeiro, v. 19, n. 3, p. 847-852, 2014. 
FERREIRA, V. F. et al. Educação em saúde e cidadania: revisão integrativa. Trabalho, Educação e Saúde, Rio de Janeiro, v. 12, n. 2, p. 363-378, maio-ago. 2014.

FLEURY-TEIXEIRA, P. et al. Autonomia como categoria central no conceito de promoção de saúde. Ciência e Saúde Coletiva, Rio de Janeiro, RJ, v. 13, n. 2, p. 2115-2122, dez. 2008.

GOIDANICH, M.; GUZZO, F. Concepçóes de vida e sentimentos vivenciados por pacientes frente ao processo de hospitalização: o paciente cirúrgico. Rev. da Sociedade Brasileira de Psicologia Hospitalar, Rio de Janeiro, v. 15, n. 1, p. 232-248, jan./jun. 2012.

GOMES, R. Análise e interpretação de dados de pesquisa qualitativa. In: MINAYO, M. C. S. (Org.). Pesquisa Social: teoria, método e criatividade. 28. ed. Petrópolis: Editora Vozes, 2009, p.79-108.

HAESER, L. de M.; BUCHELE, F.; BRZOZOWSKI, F. S. Consideraçóes sobre a autonomia e a promoção da saúde. Physis Revista de Saúde Coletiva, Rio de Janeiro, v. 22, n. 2, p. 605-620, abril/jun. 2012.

MACHADO, M. de F. A. S. et al. Integralidade, formação de saúde, educação em saúde e as propostas do SUS - uma revisão conceitual. Ciência e Saúde Coletiva, Rio de Janeiro, v. 12, n. 2, p. 335-342, 2017.

MINAYO, M. C. S. O desafio da pesquisa social. In: (Org.). Pesquisa Social: teoria, método e criatividade. 28. ed. Petrópolis: Editora Vozes, 2009, p. 9-29.

NUNES, Samantha et al. Ansiedade, depressão e enfrentamento em pacientes internados em um hospital geral. Psicologia, Saúde \& Doenças, Lisboa, PT, v. 14, n. 3, p. 382-388, 2013.

PAIM, J. et al. O sistema de saúde brasileiro: história, avanços e desafios. The Lancet [Série Brasil], p. 11-31, maio 2011.

PAULA, S. H. B. de; SILVA, A. L. da; BERALDI, R. Direito à autonomia em saúde: onde mora a vontade livre? In: KEINERT, T. M. M.; PAULA, Silvia Helena Bastos de; BONFIM, José Ruben de Alcântara (Org.). As açóes judiciais do Sistema Único de Saúde e a promoção do direito à saúde. São Paulo: Instituto de Saúde, 2009, p. 109-118.

PEDROSA, L. A. C. Ética da alteridade e respeito à autonomia na relação médico-paciente. Direito UNIFACS - Debate Virtual, Salvador, n. 187, jan. 2016.

PEREIRA, R. A. F.; KRUEL, C. S.; DOTTO, Fernanda Real. É uma doença? Sinto dor! Reflexôes sobre a experiência de hospitalização. Disciplinarum scientia, Santa Maria, v. 13, n. 2, p. 227-241, 2012.

SÁ, Marilene de Castilho. A fraternidade em questão: um olhar psicossociológico sobre o cuidado e a "humanização" das práticas de saúde. Interface - Comunic., Saúde, Educ., Botucatu, v. 12, supl. 1, p. 651-664, 2009. 
SCARPELLI, A. C.; FERREIRA, E. F.; ZARZAR, P. M. P. de A. Vulnerabilidade socioeconômica versus autonomia na pesquisa em saúde. Revista Bioética, Brasília, v. 15, n. 2, p. 298-307, 2007.

SENE, T. B. et al. Autonomia do paciente: análise situacional de uma unidade de urgência. Revista Bioética, Brasília, v. 20, n. 3, p. 520-527, 2012.

SILVA, A. M. da; SÁ, M. de C.; MIRANDA, L. Concepçóes de sujeito e autonomia na humanização em saúde: uma revisão bibliográfica das experiências na assistência hospitalar. Saúde e Sociedade, São Paulo, v. 22, n. 3, p. 840-852, 2013.

SOARES, J. C. R. de S.; CAMARGO JR., K. R. A autonomia do paciente no processo terapêutico como valor para a saúde. Interface - Comunic., Saúde, Educ., Botucatu, v. 11, n. 21, p. 65-78, jan-abr. 2007.

\section{Notas}

${ }^{1}$ Os nomes das(os) entrevistadas(os) foram alterados visando garantir o sigilo de sua identidade.

${ }^{2}$ V. de A. H. Pinto: concepção e delineamento da pesquisa, coleta, análise e interpretação dos dados; redação e do artigo e aprovaçáo da versão final. F. S. de Paiva: concepção e delineamento da pesquisa, orientação do trabalho de campo; redação e do artigo e aprovação da versão final. 


\section{Abstract}

\section{"Oh, they would definitely discharge me, right...": autonomy in the health care process of hospitalized subjects}

Autonomy is considered a fundamental human right and its promotion and enlargement compose several public health policies. This study aims to investigate the senses produced by hospitalized people in a Brazilian university hospital concerning their autonomy in the process of healthcare. The study takes on an exploratory, qualitative approach. Six hospitalized people were interviewed between July and October 2018. The interviews were transcribed and analyzed according to thematic content analysis. The results were divided into two categories: 1) The experience of illness and hospitalization; and 2) Relationship between the hospitalized person and the health team. It is considered that there are still several challenges to the co-production of hospitalized people's autonomy, such as the need to consider the vicissitudes of the hospitalization experience, as well as the fragility in the communication processes between hospitalized people and the health team. Some paths are pointed out aiming at strengthening the autonomy of hospitalized people, such as providing a health care that goes beyond the hospitalized person's illness and a professional performance based on health education practices that foster dialogue and consider the knowledge of the hospitalized people.

> Keywords: Autonomy; hospitalization; health care. 